\title{
Collaborative Avenues Created By Electronic-Learning (E-Learning) in the Study of Geography in Nigerian Universities
}

Nnenna Orieoma Emesini

Department of Educational Foundations, Ebonyi State University, Abakaliki-Nigeria

Maurice 0. Nduanya

Department of Educational Foundations, Ebonyi State University, Abakaliki-Nigeria

\section{Doi:10.5901/jesr.2013.v3n6p23}

\begin{abstract}
The study investigated the opinions of geography lecturers and students on the collaborative avenues created by e-learning in the study of geography in Nigerian universities. Two research questions and one null hypothesis guided the study. The population of the study was 1,241 Stratified Random Sampling Techniques was used to draw a sample of 366. A structured questionnaire with 14 items was the instrument used for data collection that was duly validated, and its reliability ascertained using Cronbach Alpha, which yielded an index of 0.83. 350 copies were properly filled that was used for the study. The data collected were analyzed using means and standard deviations to answer the research questions, and't' test was applied to test the hypothesis at 0.05 level of significance. The findings of the study showed that the respondents believe that the collaborative avenues created by e-learning would enhance the study of geography in Nigerian universities, making it possible for groups to work together on given projects, thereby removing boredom and isolation in the study of geography phenomena globally. It then implies that the study of geography could be enhanced through the collaborative avenues e-learning has created. Based on the findings of the study, recommendations were made.
\end{abstract}

Keywords: Electronic-Learning; Collaboration; Geography; Digitalization; Universities.

\section{Introduction}

The present era of globalization places a demand on Nigerian children to brace up in order to meet up with their colleagues in the developed world. Subsequently, the Nation's curricula need to be repositioned to meet up with the demand by re-engineering the methods, procedures and contents of all disciplines. With the modern trend of digitalization, various disciplines need to be restructured in a way to fit into the global village. The present study focuses on the discipline-geography and how e-learning can be adopted in its study in universities.

Geography is a discipline, which uses scientific methodology in finding answers to problems generated through interaction of man in the physical and social environment. It is derived from a Greek word which literally means 'to write about the earth'. Presenting a more comprehensive and concise definition, Buchanan (1974) posits that geography is the study of the diverse features on the Earth's surface, such as relief, climate, vegetation, soils, economic resources, their description, development, distribution and their interaction with man. It is a discipline that seeks to understand the world and its human and physical features through spatial location and distribution. (Routledge, Taylor and Francis, (1996). As a discipline, geography is important for the development of any society. Its worth stems from its nature as a tool for the development of the individual, and the 
entire society.

Geography teachers and authorities in the discipline according to Adinna (1990) are concentrating on the application of geography concepts in their areas of specialization. They probably do this as a way of managing the vast nature of the subject. The various segments of geography like weather and climate (Climatology); rock nature and their distribution (Geomorphology); plant and animal distribution termed (Biogeography), among other areas of geography are now taught as separate entities. This approach has resulted to a fragmental pattern of study. Minshull (1972) observes that this approach may lead to the splitting of the subject into several disciplines. Similarly, with each specialist teacher confining himself to one aspect of geography, Varma and Vedanayagam (1971) posit that the subject has been fragmented, and students are now left to fix these fragmented pieces of study in order to see their wholeness.

This approach has in a way pose a challenge for students, and in course of time, they resign to fate. Once this happens, it might result to gradual withdrawal from the subject. Akuma (2002) conducted a study on the trend of withdrawals on enrolment pattern of secondary school students in five subjects. The author discovered that out of the five subjects used for the study, geography had the least enrolment, and that teacher's ineffectiveness; wide area of coverage and shortage of qualified teachers are contributing factors to the withdrawal trend. An increasing number of geographers are now changing rapidly in their line of thought for a new method of studying geography. They are thinking of the best approach to make it attractive and competitive to our teeming youths. As a result, collaborative avenues electronic-learning (e-learning) offers to enhance geography study are being investigated. Electronic learning (e-learning) connotes learning and knowledge derived from using computer-aided gadgets (Noah, 2002). E-learning is a subset of Information and Communications Technology (ICT) encompassing the application of information technologies, and communicating same through electronic devices. E-learning might likely be a good tool for improving teaching and learning, and an access route to teaching, learning and research materials (Naidoo, 2003). Emphasizing more on the benefits of e-learning, Naidoo explains that it makes delivery of instruction very flexible, interactive, and learning, lasting. Tend in Eya (2006) simply perceives e-learning as the use of computer-aided-gadgets to aid learning. Rees, Mackay, Martins, Conole and Davis (2008) see e-learning as the application of advanced learning technology that is computer based, and that makes delivery of lesson flexible, interactive and long lasting. Eya (2006) reiterates that e-learning is the largest and the most challenging application of ICT in the delivery of education. The author sees e-learning as the process of e-literate teachers communicating with e-literate learners with up-to-date books and information using electronic skills.

E-learning with its web-based facilities provides the learners with exciting opportunities to reach for more educational information. This leads to the development of inquiry mind, creativity and good study habits. Professional isolation that many teachers suffer in the traditional classroom becomes a thing of the past. This is because e-learning connects teachers with other professional associates and colleagues worldwide (Villanueva, 2000). By so doing, teachers have access to their colleagues' study materials, methods and wealth of knowledge, and also, share their teaching experiences and challenges. With its enriched virtual classroom, e-learning provides direct interaction between teachers and learners of varied backgrounds. In the process, they share real life experiences or occurrences, and discuss events as it happens immediately. (UNESCO, 2003; Naidoo, 2003 and Nnajiofor, 2007). The above excerpts are a glimpse of the loaded benefits which e-learning provides through its collaborative avenues.

Collaboration simply implies working together as a group, or partners with like minds working together on an activity or project. Rao (2008) upholds that collaboration and team work are characteristics of the modern work environment that affords individuals the opportunity to interact with each other. The author further explains that collaborative learning is relevant for students working on a group project, as they interact and seek advice and information from each other, and from the other groups. Collaborative opportunities offered through e-learning allows teachers and 
learners to participate in various educational experiences together without regard to their physical locations, thereby improving their task performance and attitude towards learning (Nnajiofor, 2007).Corroborating this, Rao (2008) posits that collaborative avenues of e-learning build up constructive dialogue and debate among teachers and learners, and enhance interests and motivation among colleagues and peers respectively. Rees et al (2008) explains that e-learning helps in the building of "Learning Nugget Concept" which is a forum for developing collaborative work, and to develop the meta-data needed for easy transfer of e-learning materials, from one institution's virtual learning environment to another. According to the authors, the common element is the 'nuggets' which involves identifying common elements on which to base the merger, and that these nuggets contain learning materials, students' assignments and evaluation of students' achievement modules.

The world is tending towards becoming a global village through the World Wide Web (WWW) and geography, as the study of the earth as a home of man may likely be re-positioned in this village through e-learning. As earlier stated, the vastness of geography content had been a source of fear to students, and of serious concern for geography teachers. Introduction of collaborative avenues which e-learning provides might make the study of geography in our universities easier, as it will likely reduce its vastness to mere interaction and discussion classes from all sides of the globe. Hence the study sought the opinions of geography lecturers and the students, on the collaborative avenues e-learning has created in the study of geography in universities in Nigeria. Specifically the study sought to examine the opinions of the:

1. University lecturers on the collaborative avenues created by e-learning in the teaching of geography,

2. University students on the collaborative avenues created by e-learning in the learning of geography.

The study was guided by two research questions thus:

1. What are the collaborative avenues created by e-learning in the teaching of geography in Nigerian universities?

2. What are the collaborative avenues created by e-learning in the learning of geography in Nigerian universities/?

One null hypothesis was formulated for the study, and was tested at 0.05 level of significance:

There will be no significant difference in the mean opinions of university lecturers and the students, on the collaborative avenues created by e-learning in the study of geography in Nigerian universities.

\section{Theoretical Framework}

The study is based on school-centred innovation theory of Blenkin; Gwyn, and Kelly (1975) and Stenhouse (1975), which values the relationship between curriculum innovation and teachers' development. According to Stenhouse (1975:40) "Teachers are community of researchers engaged in a continuing process of enquiry into their own educational practices, developing their professional understanding as a consequence". It then means that it is through curriculum development and innovation that significant teacher development take place. School-centred innovation theory is a preferred theory for curricular innovation in teaching and learning, as it is cost-friendly, and has diverse alternatives for its information dissemination and processes, making it easy for the adoption of an innovation. Blenkin et al (1975) reiterate that for any substantial and lasting change to take place in the education system, an active involvement of the practitioners (teachers) should be considered. As a result, the collaborative avenues of e-learning being examined in the paper are an innovation that is school-based; hence, it is an off-shoot of schoolcentred innovation theory. 


\section{Methods and Procedures}

The research design used for the study is the descriptive survey type. According to Osuala (2001), a survey research is only interested in describing the status of a given phenomena as it was observed. Also Anikpo (1997) described a survey study as the use of a representative sample to examine peculiar characteristics of a given population

The area of the study is South-East States of Nigeria popularly called the "Ibo States" with teeming population of youths who are thirsty for knowledge, especially in this era of globalization. The population of the study was 1,241, made up of 61 lecturers and 1,180 students in the Departments of Geography in Government-owned Universities in the South-East States of Nigeria. The sample size for the study was 366; 61 lecturers and 305 students of geography departments. All the 61 lecturers were used for the study because their population was small. On the other hand, YaroYamene Technique for a finite population was used to draw the students' sample size of 305 for the study.

The instrument used for the data collection was a 14-itemed structured questionnaire designed by the researchers titled "Collaborative Avenues Created by E-Learning in the Study of Geography Questionnaire" (CACELSG). It was based on a 4-point scale thus: Strongly Agree (SA) $=4 p t s ;$ Agree $(A)=3 p t s ;$ Disagree $(D)=2 p t s$ and Strongly Disagree $(S D)=1 p t$. The instrument was face validated by three expert in Measurement and Evaluation and four experts in Curriculum and Teaching from Ebonyi State University, Abakaliki-Nigeria. Its reliability was also determined by administering the questionnaire to 10 lecturers and 20 students from the Department of Geography, University of Port Harcourt in Rivers State of Nigeria. The data obtained was subjected to the test of reliability using Cronbach Alpha, and it yielded a reliability coefficient of 0.92 , which was considered high enough for the instrument to be reliable. 366 copies of the questionnaire were personally administered to the students, and 350 copies were properly filled and returned, (48 copies from the lecturers, and 302 copies from the students). The data collected were analyzed descriptively using means and standard deviations to answer the research questions, while't'- test of independent samples was used to test the only null hypothesis at an alpha level of 0.05 .

\section{Results}

Table 1 presents the data that answered research questionsl and 2 .

Table 1. Opinion pool of lecturers and students on the collaborative avenues created by e-learning in the study of geography in Nigerian universities.

\section{\begin{tabular}{|l|l|l|}
\hline & Lecturers & Students
\end{tabular}



1. Make geography teachers and students to reposition themselves 3.270 .71 S.A. 3.270 .62 S.A. in their new roles as e-teachers and e-learners working together

2. Lead to geography teachers sharing their successful teaching 3.420 .65 S.A. 3.460 .75 S.A. practices with other teachers globally.

3. Lead to cooperative teaching/learning which has more positive 3.020 .81 S.A. 3.350 .72 S.A. effect on students' learning and performance

4. Enhance thoughtful conversation through its asynchronous 3.040 .82 S.A. 3.350 .72 S.A. interaction (one's own time) between learners and teachers in its world-wide network

5. Strengthen the bond between geography teachers and students, 2.941 .00 A. 3.190 .84 S.A. since it would allow deeper interaction.

6. Lead to the development of geography teaching teams and 3.270 .89 S.A. 3.370 .74 S.A. circles, that can collaborate on field work projects of interest 
globally

7. Lead to the development of deep love for, and connection with 3.040 .87 S.A. 3.230 .77 S.A. people/phenomena of other lands.

8. Enhance deeper interaction among geography students globally. 3.250 .73 S.A. 3.440 .73 S.A.

9. Enable geography teachers to be able to determine each other's 3.021 .02 S.A. 3.270 .82 S.A. relative teaching strength across the globe in terms of teaching/research outputs.

10. Enhance the creation of geography teaching circles(cooperating 3.020 .81 S.A. 3.160 .81 S.A. team teachers), which now removes isolation from their colleagues globally

11 Create unique opportunities for geography students to share their discoveries with other students globally.

12. Encourage occasional interchange of teaching/learning circles and materials in the traditional classroom.

13. Initiate the sharing of course work materials pasted in the 3.310 .66 S.A. 3.480 .68 S.A. electronic bulletin boards among the teaching/learning circles in the traditional geography classroom.

14. Encourage the exchange of research ideas and materials among 3.400 .79 S.A. 3.450 .73 S.A. the teaching/learning circles, from the e-learning class to the traditional classroom.

Grand Means $=3.173 .33$

Note: S.A. = Strongly Agree; A. = Agree

Table 1 is the summary of the opinions of geography lecturers and students on the avenues created by e-learning in the study of geography. All the items had means above 3, except item 5 of the lecturers that had a mean of 2.94; hence the grand means of 3.17 and 3.33 for the lecturers and students are recorded respectively. This shows that the respondents believe that all the enlisted are good collaborative avenues created by e-learning in the study of geography in Nigerian universities. Specifically, the lecturers and their students believe that they would be re-positioned as e-teachers working together with e-learners, with means of 3.27 respectively; an avenue created for the sharing of their successful teaching practices with means of 3.42/3.46; that another avenue created by e-learning is the development of cooperative teaching/learning, which has more positive effect on students' learning and performance, which recorded means of 3.02/3.35. Again, the lecturers and the students perceived in items 4-8 respectively, that other collaborative avenues created in the study of geography include: enhancing thoughtful conversations through its asynchronous interactions with means of 3.04/3.35; strengthening the bond between geography lecturers and students, with means of 2.94/3.19; development of geography teaching/learning teams and circles that can collaborate on field work projects of interest with means of 3.27/3.37; development of deep love for, and connection with people/phenomena of other lands, having means of 3.04/3.23, and enhancing deeper interaction among geography students globally, recording means of $3.25 / 3.44$.

Furthermore, the findings revealed that the lecturers and the students in items 9 and 10 are optimistic that they would be able to determine each other's teaching strength in terms of teaching and research outputs, with means of 3.02/3.27, and enhancing the creation of geography teaching/learning circles that could help to remove isolation from their colleagues/peers globally, with means of 3.02/3.16 is possible, as a result of the collaborative avenues created by e-learning. The respondents also envisaged the possibility of geography students sharing their discoveries with the other students globally because of the collaborative avenues of e-learning, with means of 3.31/3.48. They also saw the possibility of uploading and downloading study resources from elearning class to the traditional classroom, and the interchange of teaching/learning circles. The lecturers and their students in item 12 believe that the interchange of teaching/learning circles and materials in the traditional classroom is possible with means of $3.17 / 3.26$. In item 13, the finding 
shows that they perceived that it is possible to share course work materials pasted on the electronic bulletin boards between the teaching/learning circles in the traditional class, with means of 3.25/3.39, Finally in item 14, the lecturers and the students attest to the reality of exchange of research ideas and materials among the teaching/learning circles, from the e-learning class to the traditional class, as seen in the recorded means of 3.40/3.45. Conclusively, the findings confirm that the respondents believe that these collaborative avenues created by e-learning would enhance the study of geography in Nigerian universities.

Table 2. 't'-test analysis of geography lecturers' and students' opinions on the collaborative avenues created by e-learning in the study of geography in Nigerian universities

\begin{tabular}{lcccccccc}
\hline \multicolumn{1}{c}{ Item } & Status & $\mathbf{N}$ & $\overline{\mathbf{X}}$ & SD & Df & t-cal & $\begin{array}{c}\text { Sig.(2- } \\
\text { tailed) }\end{array}$ & Decision \\
\hline $\begin{array}{l}\text { Collaborative avenues } \\
\text { created by e-learning }\end{array}$ & Lecturers & 48 & 3.17 & 0.80 & 348 & 1.409 & \multirow{2}{*}{0.299} & Not. \\
\hline
\end{tabular}

Table 2 portrays the t-test analysis of geography lecturers' and students' opinions on the collaborative avenues created by e-learning in the study of geography in Nigerian universities. The 'sig'value as seen in the table above is 0.299 at 0.05 level of significance. The decision rule is: If the 2-tailed 'sig' value is less than 0.05 level, reject the null hypothesis, but if it is greater than the 0.05 level, then the null hypothesis is accepted. A look at table 2 above shows that the significant value' is 0.299 , which is greater than the 0.05 level. So the hypothesis is upheld that there is no significant difference between the mean opinions of the lecturers and the students on the collaborative avenues created by e-learning in the study of geography in Nigerian universities. This finding again confirms that geography lecturers and the students are optimistic that e-learning offers good collaborative avenues for the study of geography in this era of digitalization.

\section{Discussion}

A closer observation of table 1 shows that the geography lecturers and students believe that the collaborative avenues created by e-learning would help to re-position the subject better as can be perceived from the high means of 3.17 and 3.33 respectively. They believe that as e-teachers and e-learners working together from all sides of the globe, it would be easier to study geography phenomena. All the items had mean values above 3 except for item 5 on the lecturers' side. This may likely be their view points that deep interaction that may lead to bonding might not be easily established as a result of the heterogeneous nature of a university setting. On the whole, the 14 items were viewed as good collaborative avenues created by e-learning in the study of geography in Nigerian universities.

In table 1, the geography lecturers and students perceived that the collaborative avenues created by e-learning would make them re-position themselves as e-teachers and e-learners working together. This fining is in line with the views of Eya (2006) and Adimabua, Obukohwo and Okechukwu (2006) when they affirm that e-learning materials are arranged in simplified formats to make them interesting for both teachers and students as they work together. Backing up this finding, Naidoo (2003) confirms that e-learning is a medium that would help teachers and learners as they recreate their minds, as e-literate teachers communicating with e-literate learners with upto-date books and information using electronic skills. Item 2 in table 1 is on geography teachers sharing their successful teaching practices with their colleagues globally, which the respondents affirm to be true. In line with this finding, Villanueva (2000) posits that relevant educational materials are available online for teachers' successful teaching practices, which they share with their colleagues globally. Furthermore, Naidoo (2003) reiterates that e-learning is a tool that makes delivery of lesson flexible, interactive and long lasting. 
In items 3 and 4 of the table, the respondents agree that the collaborative avenues created by e-learning would lead to the development of cooperative teaching/learning with its beneficial effects on students' learning and performance, and would enhance thoughtful conversations among lecturers and students as a result of its asynchronous interaction pattern. These findings are in line with the observation of' Davis (1997); that collaboration in e-learning encourages active learning in students. Again, Villanueva (2000) maintains that the asynchronous interaction in e-learning gives students the chance to present their responses better, and by so doing, they can develop more thoughtful and creative conversations.

A run down of items 5, 6, 7 and 8 shows that they are concerned with strengthening the bond between lecturers and students; developing deep love for and connection with people/phenomena of other lands; development of teaching/learning teams and circles that can collaborate on relevant projects of interest, and enhancement of deeper interaction among geography students globally respectively. These findings of the study are in line with the views of Davis (1997) who states that e-learning creates opportunities for teaching/learning groups to work together. In the same vein, the findings are supported by the opinion of Naidoo (2003) when he explains that e-learning provides direct interaction between teachers and students of varied backgrounds across the globe, as they discuss current events. Furthermore, the findings are supported by the view points of Adimabua et al (2006), saying that e-learning is a world of community communicating, leading to the exchange of ideas and collection of materials from diverse geographical locations, thereby making the planning and execution of fieldwork a lot easier.

Items 9 and 10 of table 1 , present the opinions of the respondents on the collaborative avenues provided by e-learning for geography teachers to determine each other's teaching strength across the globe, in terms of teaching/research outputs, which they affirmed to. Rees et al (2008) confirm these findings when they made it clear that teachers and other researchers can work together to develop their study materials and contribute their intellectual quota in the teaching/learning arena. According to the authors, this is enhanced through the use of 'nuggets' which is the common elements on which mergers are based for the collaborating groups, thereby building up team spirit and cooperation which help to remove isolation and boredom in the study of some geographical phenomena The lecturers and students in item 11 believe that the collaborative avenues offered by e-learning would allow geography students to share their discoveries with other students globally. This is in line with the observations of Gomez (1994) and Dwyer and Yocam (1996) when they affirm that the e-learning forum allows students to work together, share and comment on each other's work. Finally, items12, 13 and 14 were framed to elicit the responses of the geography lecturers and students on the collaborative avenues created by e-learning in the areas of interchange of teaching/learning circles and materials in the traditional classroom; sharing of course work materials pasted in the bulletin boards among the teaching/learning circles in the traditional geography class, and encouraging the exchange of research ideas and materials among the teaching/learning circles, from the e-learning class to the traditional classroom respectively. The respondents were optimistic that these avenues created by e-learning would effectively aid the study of geography in universities in this era of globalization. In line with these findings, Davis (1997) affirms that e-learning has virtual classroom with multimedia computers for the teachers and students to work together as teaching/learning circles. The author maintains that the synchronous and asynchronous interaction modes involved can be carried further into the traditional classroom. Wiley (2000) explains that the way study and research materials are arranged in e-learning enhances interaction that can be extended beyond the electronic realm. So far from the findings of the study, the geography lecturers and students very much believe that elearning has created good collaborative avenues for the effective study of geography, thereby making it more interesting to the learners.

Table 2 presents the t- test analysis of the geography lecturers' and students' opinions on the collaborative avenues created by e-learning in the study of geography in Nigerian universities. The table shows that the 'sig.' value is 0.299 , which is greater than 0.05 level. Consequently, the 
hypothesis is accepted that there is no significant difference between the mean opinions of the geography lecturers and students on the collaborative avenues created by e-learning in the study of geography in Nigerian universities. This implies that the lecturers and the students have perceived that e-learning is a welcomed development in the study of geography in the current technological dispensation. This finding is supported by Mitchell (2007) who observes that elearning is a veritable tool in the study of geography because, it leads to the development of more collaborative learning than the traditional classroom can offer, and uses many techniques/strategies at the same time in the study of geography phenomena. The author further explains that with the 'webcam' effect of e-learning, (erosion of boundaries leading to a trend of borderless world), the various geographical phenomena are brought within a geographical space, thus making their teaching and learning stress free and manageable.

\section{Conclusion}

With the collaborative avenues created by e-learning in the study of geography, lecturers and students can connect with colleagues and peers respectively from different sides of the globe, to discuss their teaching/learning strategies, fieldwork projects of interest, and research procedures in geography. The collaborative avenues of e-learning from the findings have positive effects on both lecturers and the students in their task performances, and would help to boost their individual/group achievements. The respondents agree that the collaborative avenues created by elearning would lead to the development of cooperative teaching/learning, with its beneficial effects on students' learning and performance, and would enhance thoughtful conversations among lecturers and students as a result of its asynchronous interaction pattern, making their work loads manageable.

\section{Recommendations}

Based on the findings of the study, the following recommendations are made:

* Lecturers and students in universities in Nigeria should be properly trained in e-learning applications and its collaborative procedures to enhance university education;

* Government at all levels of education in Nigeria should be committed in the mounting of e-learning facilities to boost the digitalization of the Nigerian classrooms.

* Universities in Nigeria should work out the modalities of collaborations within and outside the country, in the study of geography and other courses offered in the institutions, using e-learning procedures.

* Some academic staff in Nigerian universities are not interested in electronic applications in teaching and learning. University authorities need to enlighten the staff on the need to brace up in this era of digitalization, in order not to be misfits in the globalization process.

* E-learning is power driven; and as such, the Federal Government of Nigeria should ensure that constant power supply and reliable standby generators are available in the universities in the country for effective e-learning application.

\section{References}

Adimabua, O.A.; Obukohwo, A.F. \& Okechuku, O.E. (2006). Re-engineering the Nigerian Education Sector Using ICT. EBSU Journal of Education, 2: 4, 131-138.

Adinna, E.N. (1990). Teaching Geography as an Applied Science: Problems and Strategies for Improvement, Journal of Studies in Education, 1: 2, 64-74.

Akuma, N. (2002). Attrition in Secondary School Enrolment in Geography: Causes and remedies, Ebonyi State University Journal of Education, 1: 1, 19-22.

Anikpo, L.C. (1997). Research Design. In: A. E. Eze; S. E. Omebe and H. O. Ezike (Eds.). Foundations of Research in Education. Enugu: Rejoint Communications. 
Blenkin, G.M.; Gwyn, E. \& Kelly, A.V. (1975). Change and the Curriculum. London: Hodder and Stoughton Group.

Buchanan, R.O. (1974). An Illustrated Dictionary of Geography (ed.) Singapore: Fep. International LtdMcGraw-Hill Far Eastern Publishing Limited.

Davis, N. (1997). Using of IT in Teaching and Learning. San Francisco: J ossey-Bass.

Eya, L.O.D. (2006). Webagogy and Educational Re-engineering in the $21^{\text {st }}$ Century: The E- Learning Agendum. Ebonyi State University J ournal of Education, 4: 2, 63-68.

Fisher, C.; Dwyer, D.C. \& Yocam, K. (1996). The Apple Classroom of Tomorrow: An Overview in Education and Technology. San Francisco: Jossey-Bass.

Minshull, R. (1972). The Changing Nature of Geography. London: Hutchison University Library.

Mitchell, D. (2007). Making the Most Use of Your Departmental Websites in Teaching Geography, Geography Education Online Journal, 32: 1, 60-62.

Naidoo, V. (2003). ICT in Education Policy-Reflecting on Key Issues. Paper Presented on ICT at a PanAfrican Workshop Held in Botswana in April.

Nnajiofor, F.N. (2007). ICT as a Vital Tool for Capacity Building and Socio-Economic Development. Nigeria. Journal of Education for Professional Growth, 3: 1, 186-192.

Noah, R. (2002). The New International Pocket Computer Dictionary. New York: Trident Press International.

Osuala, E. C. (200I). An Introduction to Research Methodology. Ibadan: African-Feb Publishers.

Pea, R. D.; Edelson, D.C. \& Gomez, L.M. (1994). Distributed Collaborative learning Using Scientific Visualization and Wideband Telecommunication. Paper Presented at the $160^{\text {th }}$ Meeting of the Association for the Advancement of Science on 22nd February.

Rao, V. K. (2008). Educational Technology. New Delhi: A.P.H. Publishing Corporation.

Rees, P.; Mackay, L.; Martin, D.; Conole, G. \& Davis, H. (2008). Developing E-Learning in Geography. London: Routledge.

Routledge, T.; Taylor, F. \& Francis 0. (1996). Information World. ( http://www informationworld.com /smpp/content). Retrieved on 15/08/08

Stenhouse, L. (1975). An Introduction to Curriculum Research. London: Heinemann Books Ltd.

UNESCO. (2003). Bulletin on Projects in ICT Policy, Teaching and Learning. Paris: UNESCO Press.

Varma, O.P and Vedanayagam, E.G. (1971). Geography Teaching. New Delhi: Sterling Publishers Private Ltd. 
